\title{
The Reform Strategy of Electricity Market under New Circumstance
}

\author{
Xin Zhang ${ }^{a}$, Dongqiang Heng ${ }^{b}$, Lei Zhang, Shuzhe Li \\ State Grid Henan Electric Power Company Luoyang Power Supply Company, Luoyang 471000, \\ China \\ aeadie@163.com, ${ }^{\mathrm{b}} 1015903240 @ q q . c o m$
}

Keywords: Reform, electricity market, circumstance.

\begin{abstract}
It is the direction of the global power industry that market-oriented reform of the power industry. Although the ways in which States electricity reform, basic, pattern design vary, but the goal of power industry reform are the same, is to break the monopoly and introducing competition mechanism, improve efficiency, reduce social costs (including electricity costs, resource costs, environmental costs, etc.).Combined with the actual situation of the domestic power sector reforms, the process of reform and development of China's power market rules of electricity are discussed and research.
\end{abstract}

\section{Introduction}

Electricity market reform practice over the years has proved that each country's power industry to market-oriented process is not the same, not only is a gradual reform process, but also a market operation mode evolving process. Due to different starting point, the ultimate goal is different, our market-building power cannot copy the experience of foreign countries, the need for in-depth analysis of the status quo situation and power industry in our country, the lessons learned from foreign electricity markets, in order to find our own Road power industry reform, electricity market rules for determining various stages of market development.

\section{Electricity Market Operation Rules to Overview}

Operating rules of the electricity market is the electricity market construction, management, organization and operation of norms and guidelines. It describes the operating rules constitute the framework of the electricity market, market management, transaction type, competition pattern, market operation, metering, settlement payment, communication and information dissemination, market intervention and market disruption and so on. Specific forms of electricity reform countries, is to establish a set of power market trading system, through open market-oriented business model, the introduction of competition, lower costs, the rational allocation of resources, and ultimately benefits users. Different stages of electricity reform, different levels of the market, the different objectives of the reform, different national conditions, will produce different electricity market operating rules with adaptation.

Our electricity market operating rules should contain the following:

(1) General. The purpose of the development of operating rules, principles, roles, rules applicable range.

(2) Market management. Consisting of market participants; to enter the market and out of the market conditions and legal procedures: market members who (grid operation and generation companies) duties, rights and obligations; market management agencies, and regulators.

(3) Pre-scheduling program. Load forecasting tools and methodologies adopted by stakeholders forecasting, prediction time. Publishing forecast results. Effective time reporting, procedures and time modify the declaration of turbine technology and economic data, check the declared data, quotes release, transfer and validation, offer confidentiality. to develop pre-scheduling program. To contribute to program into unconstrained and constrained output planned in two stages. Press each time price and other data generation enterprise reporting, and each time the two load electricity needs, 
develop plans for each unit output. It makes provision for financial compensation of by the constraints of the unit according to security check when adopted, including off stop and make provision for financial compensation. It should also include a unit maintenance plan.

(4) Scheduled to run. Should include the implementation of the principle of the schedule, modify the pre-scheduling principles, methods and procedures; investment unit AGc function; spinning reserve capacity to ensure grid; the grid area voltage control: the unit falling output and temporary troubleshooting declaration and approval; principles and steps of the grid incidents; on disobeys the dispatch order processing and much more. For pre-scheduling changes to two cases to deal with; one pre-scheduling and the actual situation of the deviation is small, that is, the deviation can be adjusted by rotating the alternate scenario; the second is the pre-scheduling and the actual situation of large deviations, has been Unable to ensure grid security and reliable power supply situation by adjusting the spinning reserve and the existing unit output. For crew scheduling assessment should include the: Under what circumstances the unit needs assessment to be made; how to provide AGC, standby, FM, reactive and other types of units into line assessment to be made; to provide for the punishment of the accident unit and much more.

(5) Network security. Should include the status of the security provisions of the grid; the grid security incidents affecting the proceedings; generating corporate responsibility;; grid dispatch center to maintain the safe operation of the power grid of the duties and obligations to maintain the contents of the principles and measures for the safe operation of the grid.

(6) Bidding mode. The main auction model should include (such as the current pilot provinces adopted "unit at different times for each transaction B bidding power generation, co-back power by closing settlement price pigsty, spot electricity price settled by competitive auction," the limited auction model) and its to provide for the operation; special units (such as thermal units, wind turbines, pumped storage units, oil fuel units, the original contract cannot change the foreign units, etc.) to make special provision auction model; power grid enterprises and power companies signed each year time of purchase and sales contracts and contract (including power unit annual contract, the contract price, the equivalent availability factor assurance unit and assigned an annual contract value of the number of days of electricity contents) be made; how to determine the contractual arrangements planned trading day electricity unit make provision for combination; how to carry forward the power unit of the Contract (unit due to a failure and other reasons not made enough electricity contracts) provide much more.

\section{Problems of Electricity Market Reform}

As China's electricity market reform is still at the preliminary exploration stage, many of the problems are inevitable, summed up roughly mainly in the following questions:

(1) Government role and status in the reform of the electricity market in the not yet completely clear, and electricity regulatory agencies appear manifold electrical phenomena, locate parts of some government departments needs to be further clarified to avoid some of the specific issues that no one management in some areas, some Management too much area the phenomenon of death.

(2)Provincial guidelines for the development of the entity cannot be achieved on resource optimal allocation of national significance, leading to the provinces the expense of others, close inter-provincial resource market.... "Provincial entity" approach to development in order to solve the power shortage problem historically played a major role, but in the new context of power supply and demand balance has become a major obstacle to market competition and trans-optimal allocation of resources. To protect the local power will not be considered from the economic power exchange between provinces between provinces. This also shows that the current lack of legal power transactions of a buyer's market, there is no mechanism to establish rules to price competition to the allocation of resources.

(3) The original tariff approval mechanism outdated, market allocation of resources function need to strengthen. The traditional approach to tariff approval continues today by government price department to the project cost, profit inverse price, not only completely out of the changes in supply 
and demand of the market, does not reflect the wishes of consumers, but also hidden a huge excess profits for power plant powerless.

(4)Assets bond has not really been fully established, even in some areas disguised resurgence trend. Since power plants and power grid is not completely stripped of property rights, most power companies still retain a small amount of power generation capacity, power companies invest in electric three production companies have not been effectively curbed, originally planned to be classified as secondary industry group of generating units still in power grid company under the jurisdiction to intervene in the policy or other asymmetric information, policy power plant dispatch center scheduling arrangements offer the market may not fully comply with the operational guidelines, is not conducive to the "Excellencies," scheduling realization of the principle.

(5)Due to limitations of market scale, market-oriented operation to achieve a portion of electricity needs and existing contracts to buy electricity system of coordination, leading to limited competition or insured competition, market downsizing, theoretical research and trading algorithm design to bring greater impact. Meanwhile, the price of the result of competition cannot really reflect the changes in market demand, difficult to analyze on the "Excellencies," scheduling principles of execution and market indicators to judge. In addition, under the two-track settlement of electricity limited competition mode, since $90 \%$ of the basic power of the profits attract, target bidding strategy becomes grab power generation, resulting in a low offer. Historically grab more power generation unit will be further reduced offer, resulting in a vicious competition.

\section{Solve the Problem of China's Power Reform of the Basic Ideas and Directions}

By studying the experiences of Electricity reform and the reform of China's power market exposed the current problem can be summed up China's power reform to solve several issues to be resolved in the basic ideas and direction:

(1)Governments need to be clearly defined position in the electricity reform, strong organization and promotion of electricity reform, good service and the development of supporting regulations .China's current electricity tariff and regulatory functions of the infrastructure investment in the central and provincial government departments and the price department plans to develop, while the electricity market regulatory functions located in the Economic and Trade Commission and the Central Electricity Regulatory Commission and the provincial government. To make the electricity market regulatory functions and institutions is relatively concentrated and opposition to reform the existing regulatory model, through legislation (Electricity Regulatory Committee Organization Law, Electricity Regulation Act), the establishment of the Electricity Regulatory Commission, and determine the open and transparent regulatory process, strengthen the power functions of the regulatory committee, a clear management responsibilities. In addition, efforts to achieve market leading to optimal allocation of resources, reducing planned economic characteristics of the approval system applicable to the scale, and gradually promote the approval system and filing system for administrative jurisdiction, the public system of social restrictions of electricity infrastructure investment, increased sun management, and take advantage of generating corporate governance structure.

(2)Breaking the barriers between provinces market, achieve cross high voltage grid interconnection. According to the process of national electricity reform, the provincial electricity market development for the physical separations will be broken and the first step will be to achieve a large district-level electricity market, ultimately with the formation of a national network of the national electricity market. Different size of the market area, decided to set up their regulatory bodies and El scheduling regular market different operating modes, different levels of complexity of market transactions (such as large-area electricity market will consider the electricity trading large range of focal line)

(3)Develop mechanisms tariff reform in the electricity market reform carried out various measures in the first tariff reform. Target price reform are: competition sector use of market price competition, monopoly departments to achieve the principle of marginal cost price controls; the implementation of 
a system or part electricity price, seasonal and TOU pricing, "competitive prices", according to demand characteristics of the user's fee charged to recover the full cost of transmission with power; for all users a fair, just, removal of subsidies. Rationalize the relationship between the price of electricity under the jurisdiction of the various government departments in the structure, in the system through the development of laws to regulate the price of electricity tariff reform process.

\section{Summary}

In this paper, China's power market reform to solve the problem in the basic ideas and direction. To solve these problems, we need to do a few points: the correct positioning of the government, the establishment of service-oriented government; to break the inter-provincial market barriers and achieve cross high voltage grid interconnection; develop mechanisms tariff reform, the first to carry out tariff reform; strengthen legislation to protect, so according to the law of electricity, according to the law reform; truly private mechanisms; accelerate the commercialization and corporatization reform; changes in transaction settlement, the real competition.

\section{Reference}

[1] Ren J Q, Fang C Y. Experience and Enlightenment on the Reform of Foreign Electric Power[J]. Journal of Beijing Jiaotong University, 2004.

[2] Pollitt M. Electricity Reform in Chile - Lessons for Developing Countries[J]. J.network Ind, 2004.

[3] And, R. W. B., \& Besantjones, J. (2002). Global electric power reform, privatization, and liberalization of the electric power industry in developing countries1. Annual Review of Energy \& the Environment(1).

[4] Williams J H, Ghanadan R. Electricity reform in developing and transition countries: A reappraisal[J]. Energy, 2006, 31:815-844.

[5] Jamasb T, Mota R, Newbery D, et al. Electricity sector reform in developing countries : a survey of empirical evidence on determinants and performance[J]. Michael Gerald Pollitt, 2005. 